\title{
Fatigue Strength Analysis of S34MnV Steel by Accelerated Staircase Test
}

https://doi.org/10.1515/eng-2020-0048

Received Jan 03, 2020; accepted Mar 12, 2020

\begin{abstract}
This paper presents the reliability estimation of fatigue strength of the material used for crank throw components. The material used for crank throw components is forged S34MnV steel and subsequently heat-treated by normalising and tempering. High cycle fatigue testing under fully reversed cycling $(R=-1)$ was performed to determine the fatigue limit of the material. The staircase test method is used to obtain accurate values of the mean fatigue limit stress until a number of cycles up to 1E7 cycles. Subsequently, the fatigue test results depend strongly on the stress step and are evaluated by the Dixon-Mood formula. The values of mean fatigue strength and standard deviation predicted by the staircase method are $282 \mathrm{MPa}$ and 10.6 MPa, respectively. Finally, the reliability of the design fatigue strength in some selected probability of failure is calculated. Results indicate that the fatigue strength determined from accelerated staircase test is consistent with conventional fatigue testing. Furthermore, the proposed method can be applied for the determination of fatigue strength and standard deviation for design optimisation of S34MnV steel.
\end{abstract}

Keywords: Crank throw, Fatigue strength, S34MnV steel, Staircase test

\footnotetext{
*Corresponding Author: Rando Tungga Dewa: Regional Technological Institute, University of West Bohemia, Pilsen 301 14, Czech Republic; Bina Nusantara University, Faculty of Engineering, Jakarta 11480, Indonesia; Email: rando.td@gmail.com; rando@rti.zcu.cz

I. M. W. Ekaputra: Mechanical Engineering Department, Sanata Dharma University, Paingan, Maguwoharjo, Depok, SlemanYogyakarta 55282, Indonesia

Gunawan Dwi Haryadi: Mechanical Engineering Department, Diponegoro University, Jl. Prof. Sudharto, SH., TembalangSemarang 50275, Indonesia

Seon Jin Kim: Mechanical Design Engineering Department, Pukyong National University, Busan 48547, Republic of Korea
}

\section{Introduction}

S34MnV steels are widely used as necessary materials in crankshaft manufacturing of large-size marine diesel engines. Crankshaft transforms the reciprocating motion of pistons into rotary motion and experiences a large number of loading cycles during its service life. For those mechanical components subjected to repetitive stress probably will fail with stress much lower than that of the yield stress or a single load to fracture. Therefore, fatigue failures occur after a long period of service used $[1,2]$.

The fatigue phenomenon is a process of damage caused by crack growth due to the repeated cyclic stress within the material elastic zone. Advances in understanding the fracture surfaces are of importance. The literature reviews have developed the new characterisation technique adopting fractal theory concept that can be utilised to reveal the characteristic lengths of a fracture surface and contribute to a better understanding of the influence of microstructure on fracture processes [3, 4]. However, this study is focused on the evaluation of the fatigue strength of the crankshaft components to secure its safety and reliability. Due to the variation on material properties (i.e. microstructure, defects, flaws, etc.), their fatigue resistance can have a significant difference in terms of several cycles to failure. Thus, statistical information according to the of fatigue properties is required when fatigue failure is deeply involved in safety and reliability [5, 6]. One of those properties is fatigue strength that can be treated as a single random variable, which fluctuates stochastically. Although the famous S-N curves can be able to represent the fatigue properties of the material, the variation in fatigue life is still unknown. In general, there are extensive kinds of literature in probability theory concerning the solution for bandit problem by clustering distribution [7], collaborative filtering [8], an online optimisation method for the quantification problem [9], and so on. Those might work to stochastically determine the fatigue strength from a set of data, i.e. exploitation of the specific value that has the highest probability of occurrence and exploration to get more information about the expected value from a collection of data. To the best of our knowledge, however, the

๑ Open Access. (c 2020 I. M. W. Ekaputra et al., published by De Gruyter. 
fatigue life distribution is often described in the form of Weibull distribution. In contrast, the fatigue limit can be described in the way of the algebraic normal distribution function.

Literature studies revealed that the newly developed staircase testing could be used for the sake of time-saving even on high cycle fatigue to ultrasonic fatigue test. Morrissey et al. [10] showed that staircase testing was wellimplemented through gigacyle regime. Wallin [11] reported that staircase testing could be considered an effective method for the estimation of the fatigue strength with presently most common Dixon and Mood approach with the assumption that the threshold stress follows a normal distribution. In this study, the authors employed the accelerated procedure to fatigue strength testing, namely the staircase test. The staircase test is used to obtain the mean fatigue strength and its standard deviation. The staircase method utilises a simple protocol for specimen tested at a given starting stress for a specified number of cycles or until failure. If the specimen survives, the stress level is increased for the next specimen; likewise, the stress is decreased if the specimen fails. This method is found to be able for accuracy and time also cost-efficient for estimation of the mean fatigue strength. Therefore, this study aims to estimate the fatigue strength through staircase method of parts material of diesel engine crankshaft made of S34MnV forged steel. Lastly, we perform Monte Carlo simulations in the distribution of mean fatigue strength and standard deviation to have the reliability of fatigue design.

\section{Experimental Methods}

The material used in this study was forged S34MnV steel. The chemical composition (wt.\%) of the S34MnV steel is $0.44 \mathrm{C}, 0.26 \mathrm{Si}, 1.0 \mathrm{Mn}, 0.012 \mathrm{P}, 0.002 \mathrm{~S}, 0.12 \mathrm{Cr}$, and $0.06 \mathrm{~V}$. After the forging process, the heat treatment of the material was conducted with normalizing at $880^{\circ} \mathrm{C}$ for 17 hours and also tempering at $600^{\circ} \mathrm{C}$ for 17 hours, followed by rapid cooling.

Figure 1 shows the shape and dimension of the cylindrical fatigue specimen. The fatigue test by the staircase method was carried out at room temperature under the condition of sinusoidal waveform under fully amplitude axial load control and with constant amplitude load at 20 Hz. Table 1 shows the testing condition and matrix of the present investigation. Figure 2 shows specimen and jig configuration on servo-hydraulic equipment (MTS Landmark).

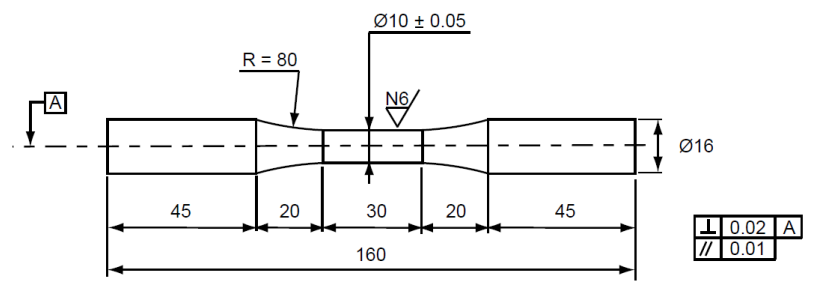

Figure 1: Cylindrical fatigue specimen shape and dimensions (in millimetre).

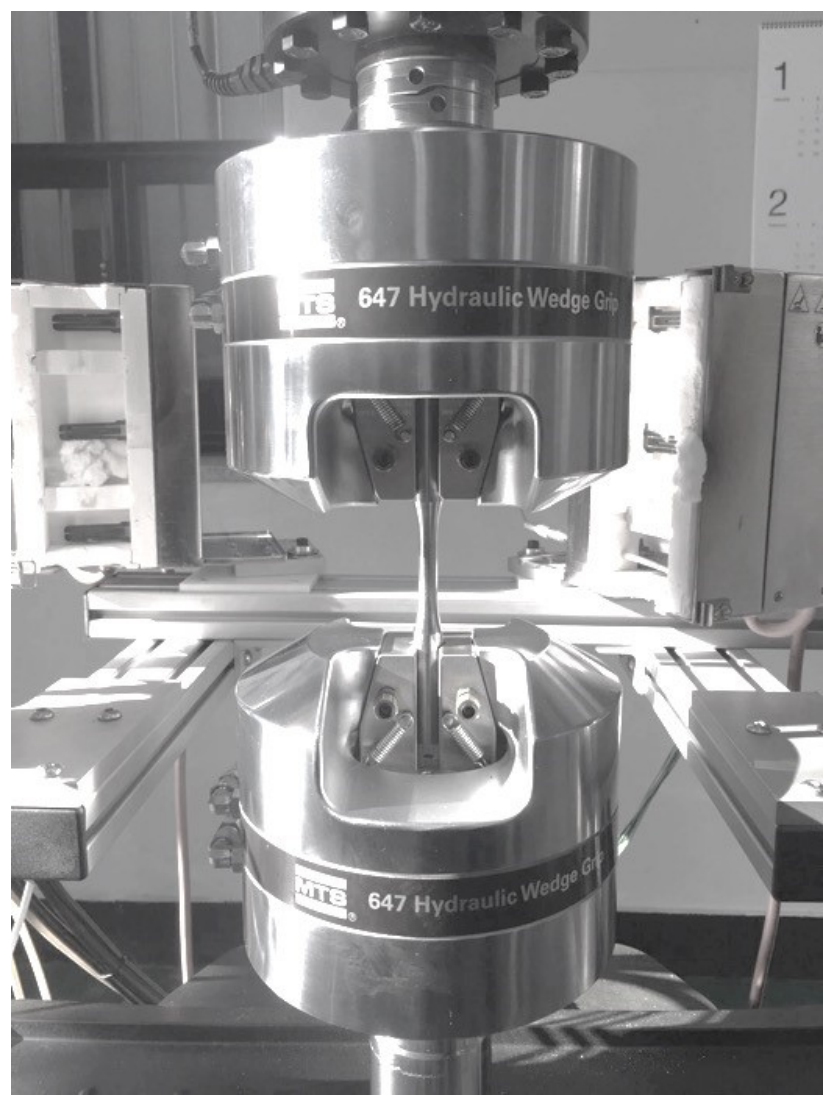

Figure 2: Specimen and jig configuration on servo hydraulic equipment.

Table 1: Test matrix for fatigue strength evaluation by staircase method.

\begin{tabular}{cc}
\hline Test matrix & Value \\
\hline Fatigue test & Load controlled \\
Waveform & Sine tapered \\
Frequency & $20 \mathrm{~Hz}$ \\
Stress ratio, $\mathrm{R}$ & -1 \\
Mean stress & 0 \\
Step size & $20 \mathrm{MPa}$ \\
Starting stress & $260 \mathrm{MPa}$ \\
\hline
\end{tabular}




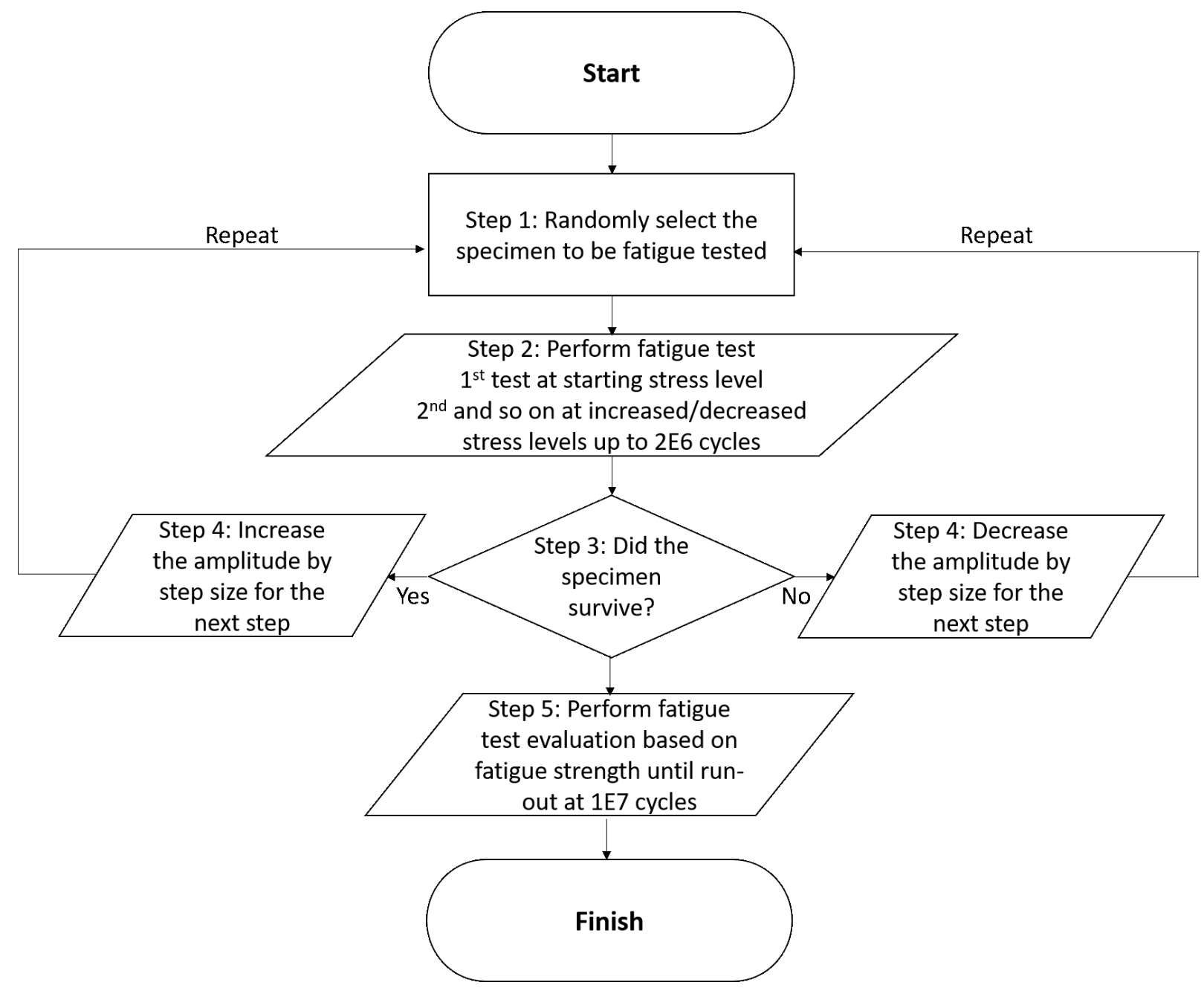

Figure 3: Flow chart of fatigue testing procedures using the staircase method.

All experiments were performed according to ISO 1099 [12]. The fatigue test procedure presented in this study is shown in Figure 3. Finally, the estimated fatigue strength of the material was verified by performing a fatigue runout test up to 1E7 cycles at the design fatigue strength of $2.3 \%$ probability of failure.

As mentioned above, the present research was conducted in the form of pass or fail mode. It is noted that the initial stress level is essential. It can be determined from preliminary S-N data or by experience. However, in this study, the tensile tests have been firstly conducted to determine the initial stress amplitude level, which is $40 \%$ of the tensile strength. The obtained mean tensile strength of $\mathrm{S} 34 \mathrm{MnV}$ steel used in this work is $649 \mathrm{MPa}$. Therefore, the initial stress amplitude equals $260 \mathrm{MPa}$. The stress level for the next specimen is tested by increasing or decreasing of the given step size $(\Delta S)$ depending on whether the original specimen is alive or failing. This process continues for all assigned specimens. Typically, the step size, $\Delta S$, is always the same value at the next stress level. It is common to take an amount that is usually close to the standard deviation of the fatigue strength. The selected step size in this study is $20 \mathrm{MPa}$.

If the first specimen survived to the expected number of fatigue limit, 2E6 cycles in this study), the next specimen is tested at the stress level increased by $\Delta S$. In other cases, if the specimen fractured before its life expectancy, thus, it will continually test at the stress level reduced by $\Delta S$. This method relies on previous experimental results. The fatigue test was carried out up to the $12^{\text {th }}$ test piece according to the above procedure.

The following equation can determine the mean fatigue strength and standard deviation.

$$
\begin{gathered}
\mu=S_{0}+\Delta S\left(\frac{A}{F} \pm \frac{1}{2}\right) \\
\sigma=1.62 \Delta S\left(F_{B A}+0.029\right) \text { if } F_{B A} \geq 0.3 \text { or }
\end{gathered}
$$




$$
\begin{gathered}
\sigma=0.53 \Delta S \text { if } F_{B A}<0.3 \\
F_{B A}=\frac{F B-A^{2}}{F^{2}} \\
A=\sum_{j=0}^{j_{\max }} j \times n_{j} \\
B=\sum_{j=0}^{j_{\max }} j^{2} \times n_{j} \\
F=\sum_{j=0}^{j_{\max }} n_{j}
\end{gathered}
$$

Where $S_{0}$ is the minimum stress amplitude corresponding to the less frequent occurrence of fractured and survived specimens, parameter $j$ is an integer representing the stress amplitude level, $n_{j}$ is the number of specimens in the less frequent event at the stress amplitude level of $j$. The plus sign (+) in Equation (1) is used for events where survival is less frequent (i.e., events, where most fractured, is occurring), and the minus sign (-) is a case where events are less frequent (i.e., events in which survival is most likely to happen).

\section{Results}

Figure 4 shows the fatigue test results obtained by the staircase method with a starting level of stress amplitude equals $260 \mathrm{MPa}$. The corresponding stress amplitude levels of the fatigue test were $260,280,300 \mathrm{MPa}$, respectively. The fatigue test results depend strongly on the stress step. And from the results, the number of survived specimens up to 2E6 cycles (indicate by $\mathrm{O}$ sign) are seven specimens, and the number of fractured specimens (denote by X sign) is five. The parameters of $j$ and $n_{j}$ by Dixon and Mood approach corresponded to the test results are summarised in Table 2.

Table 2: Parameters of $j$ and $n_{j}$ by Dixon and Mood approach.

\begin{tabular}{ccccc}
\hline $\begin{array}{c}\text { Stress amplitude } \\
(\mathbf{M P a})\end{array}$ & $\boldsymbol{j}$ & $\boldsymbol{n}_{\mathbf{j}}$ & $\begin{array}{c}\boldsymbol{A} \\
\left(\boldsymbol{j} \times \boldsymbol{n}_{\mathbf{j}}\right)\end{array}$ & $\begin{array}{c}\boldsymbol{B} \\
\left(\boldsymbol{j}^{2} \boldsymbol{x} \boldsymbol{n}_{\mathbf{j}}\right)\end{array}$ \\
\hline 300 & 2 & 3 & 6 & 12 \\
280 & 1 & 2 & 2 & 2 \\
260 & 0 & 0 & 0 & 0 \\
Total & - & 5 & 8 & 14 \\
\hline
\end{tabular}

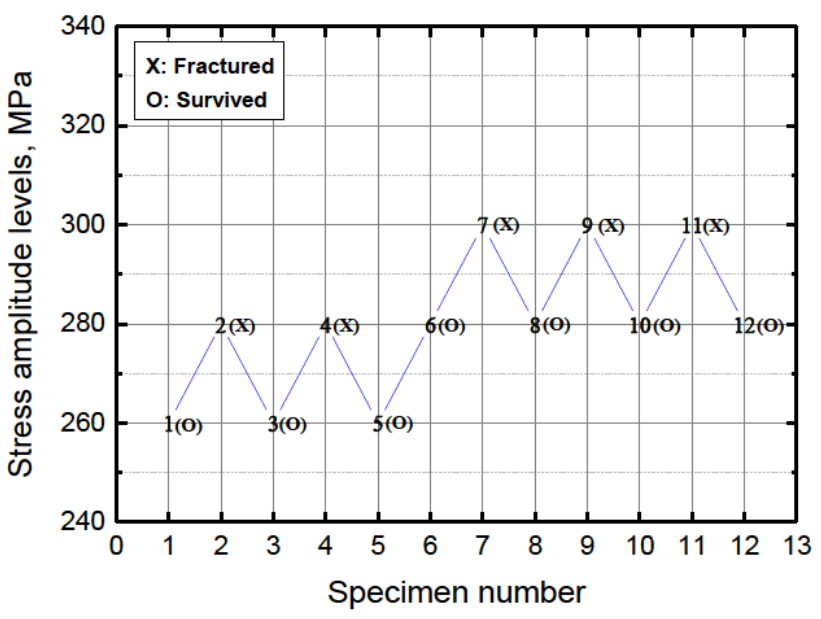

Figure 4: Staircase test results of S34MnV steel.

Table 3: Summary of fatigue test results by staircase method.

\begin{tabular}{lcc}
\hline & Value & Remarks \\
\hline No. of cycles & $2 \mathrm{E} 6$ & $N$ \\
Lowest stress level (MPa) & 260 & $S_{0}$ \\
Stress step (MPa) & 20 & $\Delta S$ \\
Failure/Run-out & 0.5 & x(factor) \\
Mean fatigue strength (MPa) & 282.0 & $S_{m}$ \\
Standard deviation (MPa) & 10.6 & $S_{t d}$ \\
Probability of survival & $97.7 \%$ & $P$ \\
Design of fatigue strength $(\mathrm{MPa})$ & 260.8 & $S_{d}$ \\
\hline
\end{tabular}

$\mathrm{A}, \mathrm{B}$, and $\mathrm{F}$ parameters estimated from Equations (5$7)$ are 8,14 , and 5 , respectively. Hence, the mean fatigue strength and the standard deviation can be calculated, which are 282 and $10.6 \mathrm{MPa}$, respectively. Table 3 shows the experimental results of the staircase method. Furthermore, the reliability of the fatigue strength can be predicted by using above-summarised values.

\section{Analysis and Discussions}

Failure analysis is of prime importance for any accurate and reliable analysis based on historical processes. Samples were taken from the macro-image of fractured specimens tested at 280 and $300 \mathrm{MPa}$. Figure 5 shows macroimage of fractured fatigue specimens tested at 280 and 300 $\mathrm{MPa}$, respectively.

One can determine that materials failed by fatigue are to examine their fractured surfaces. It is observed that the failure location was taking part at the centre of the specimen's reduced section, indicating no such buckling defor- 

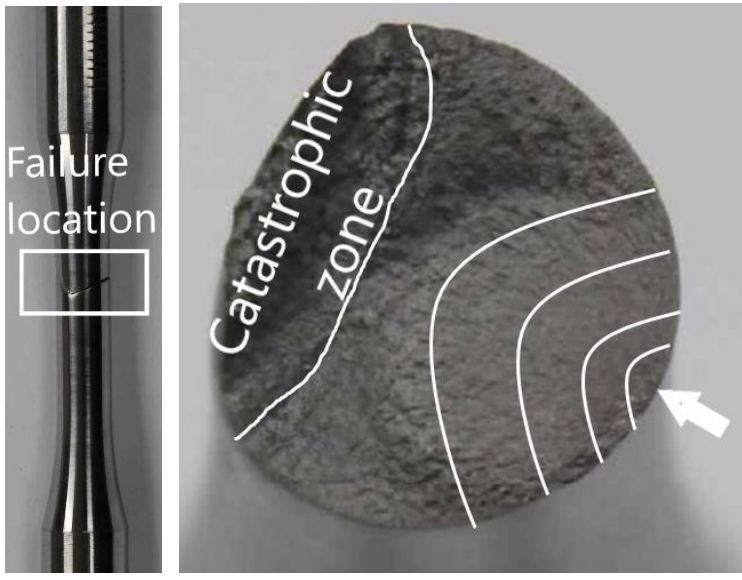

(a)
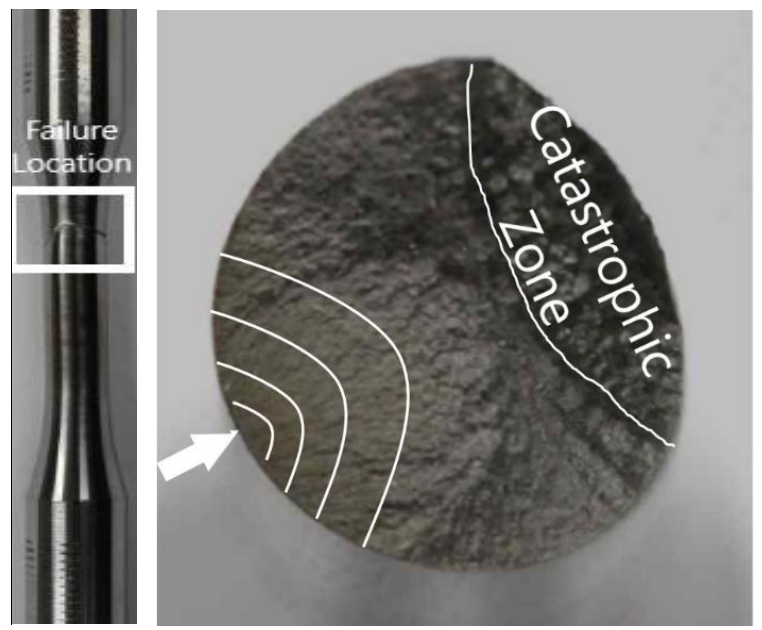

(b)

Figure 5: Macro-images of fractured fatigue specimens at: (a) 280 $\mathrm{MPa}$, and (b) $300 \mathrm{MPa}$.

mations affect. From the figure, the crack initiation (shown by the white arrow) took time to develop from the smoothsurface specimen. Afterwards, crack grew with specific fatigue crack growth rate along with the clamshell markings (fatigue beachmarks) at the fatigue surface with vary in magnitude, in this case, associated with a stress step size. Finally, the catastrophic zone shown by the rapid failure of the specimens can be observed. No evidence of the specimen defect or premature failure can be seen, other than classical fatigue fracture developed from dislocation movement of slip bands. It can be evidenced by the location of the fatigue crack initiation, which is initiated from the edge of the surface. Fatigue strength is closely related to the physical damage of material and can be defined from material structure barriers. These barriers are influenced by loading mode, stress level, and environmental effects.
Furthermore, to provide statistical information, the normal distribution is made from the quantification of the mean fatigue strength and standard deviation. Figure 6 shows the probability distribution function (PDF) of the data distribution. Results of the normal PDF can be expressed as:

$$
f_{x}(x)=\frac{1}{\sqrt{2 \pi} \sigma} \exp \left[-\frac{(x-\mu)^{2}}{2 \sigma^{2}}\right]
$$

Figure 6 exhibits the PDF curve of the fatigue limit with mean fatigue strength of $282 \mathrm{MPa}$ and a standard deviation of 10.6 MPa. It should be noted that the stress amplitude levels cause these statistical parameters for the survived specimen and the less frequently occurring events of the fractured specimen. Furthermore, the design of fatigue strength for some reliability values are estimated and shown in Table 4. From the results, it is observed that the design of fatigue strength values can be predicted stochastically for the crankshaft component corresponding to the probability of failure or reliability. For example, the design fatigue strength of $95 \%$ survival is estimated to be 264.5 MPa. It is understood that the fatigue damage process must be determined statistically. This estimation confirms that the fatigue strength cannot be deterministically verified from single-test data, even though, the value is reasonable and can be derived from probabilistic SN curve, Monte Carlo technique, and staircase method.

From staircase testing, the design of fatigue strength at $97.7 \%$ of survival was calculated to be $260 \mathrm{MPa}$ based on the PDF of the experimental data. Therefore, fatigue tests were performed on three specimens up to $1 \mathrm{E} 7$ cycles to verify the assumption. Table 5 shows the entire test specimens

Table 4: Design of fatigue strength for some reliability values based on current results.

\begin{tabular}{cc}
\hline Probability of survival (\%) & $\begin{array}{c}\text { Design of fatigue strength } \\
\text { (MPa) }\end{array}$ \\
\hline 90.0 & 268.4 \\
95.0 & 264.6 \\
97.0 & 262.1 \\
99.0 & 257.3 \\
99.9 & 249.2 \\
\hline
\end{tabular}

Table 5: Results of verification test for run-out at 1E7 cycles.

\begin{tabular}{ccc}
\hline Stress level & Specimen & Results \\
\hline $260 \mathrm{MPa}$ & 13 & Survived \\
& 14 & Survived \\
& 15 & Survived \\
\hline
\end{tabular}




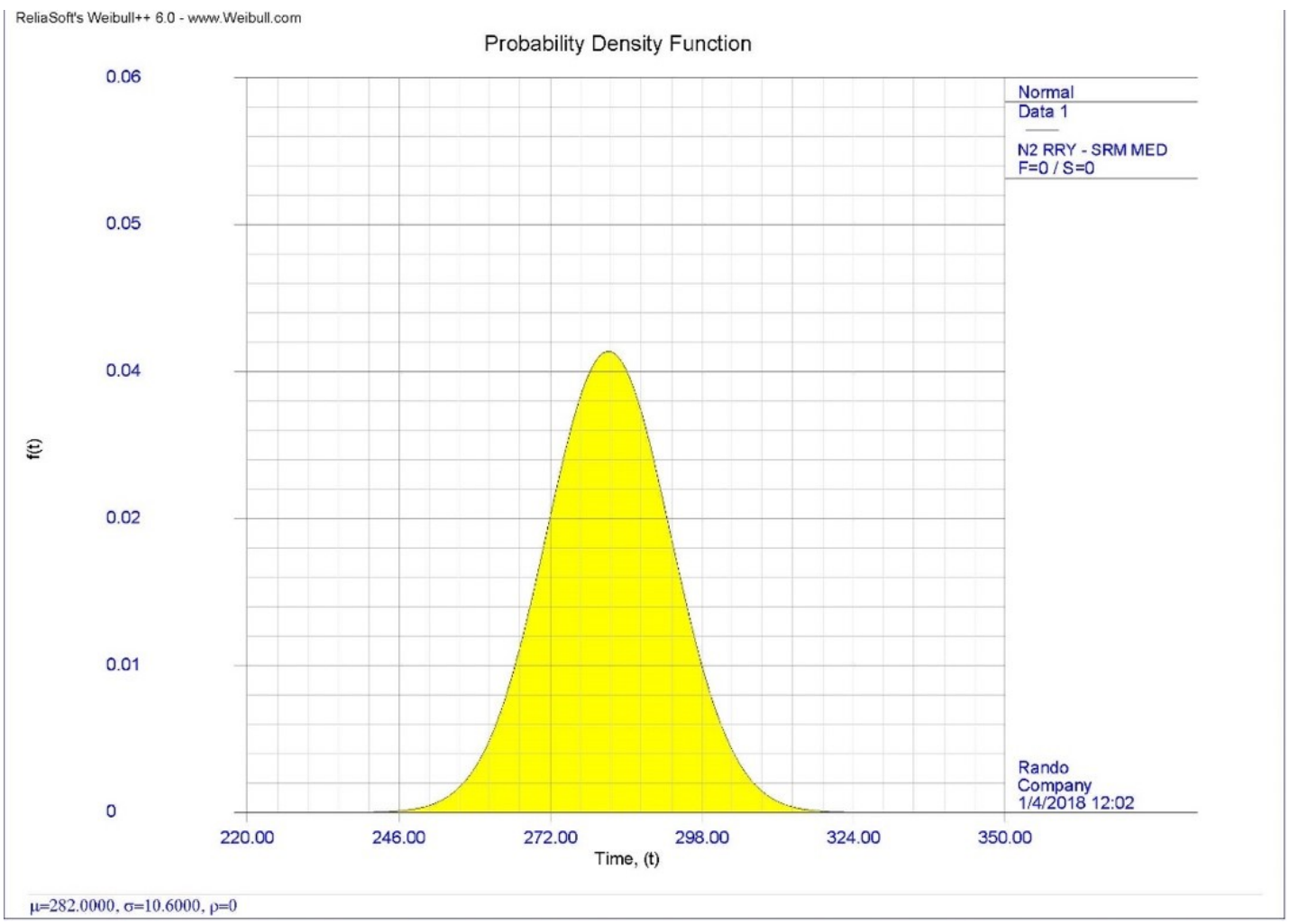

Figure 6: Probability density function of mean fatigue strength of tested material.

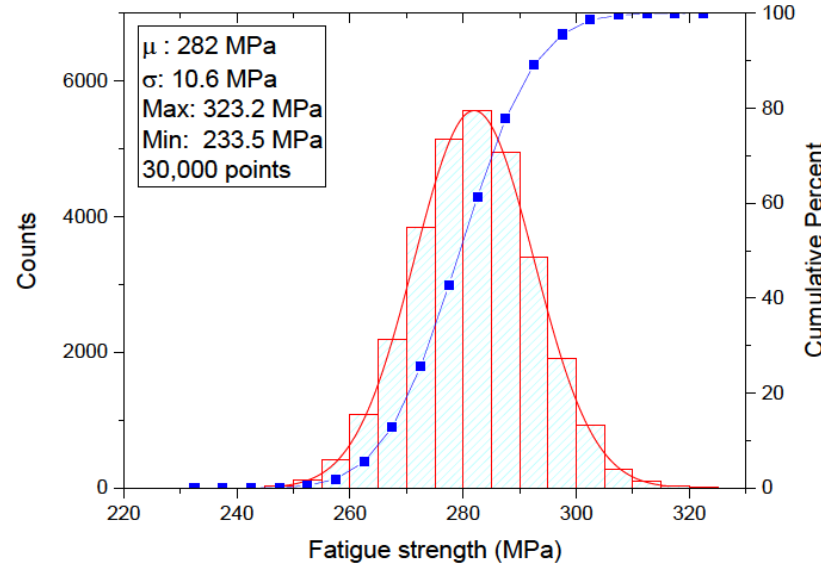

(a)

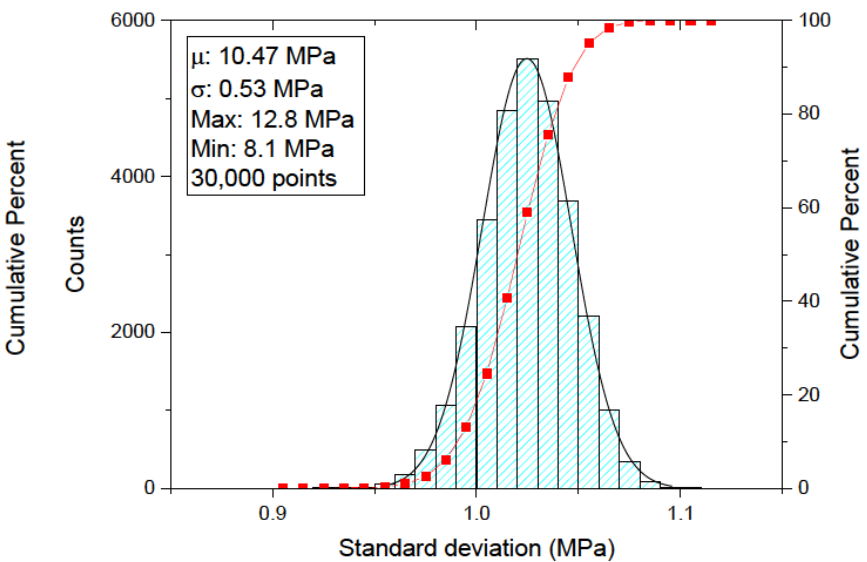

(b)

Figure 7: Monte Carlo simulation for 30,000 points for: (a) Normal distribution function of fatigue strength, and (b) Log-normal distribution function of standard deviation.

were run-out without fracture until 1E7 cycles. Thus, the reliability of the design fatigue limit of crankshaft component is satisfied.

In this study, we further perform the Monte Carlo simulations for 30,000 points to generate a dense distribution of fatigue strength and standard deviation, respectively. In the case of fatigue strength, the normal distribution can be valid to describe the data distribution. The standard deviations must be separately described in lognormal distribution $[13,14]$. This assumption can be justified from the variations of components or within the heat treatment products, although, they might be composed of the same material and manufacturing process [13]. Results of the lognor- 
mal PDF can be expressed as:

$$
f_{x}(x)=\frac{1}{x \sqrt{2 \pi} \sigma} \exp \left[-\frac{(\ln x-\mu)^{2}}{2 \sigma^{2}}\right]
$$

Figure 7 shows generated Monte Carlo simulations for mean fatigue strength and standard deviation, respectively. The results are based on random processes. Therefore, the statistical analysis with confidence values is recommended to obtain reliable results. Summaries results, PDF and the cumulative distribution function (CDF) can be seen in the figure. From the estimated data distribution, it is shown that with the massive amount of sample size, the mean of fatigue strength and standard deviation (282 MPa and $10.47 \mathrm{MPa}$, respectively) are closer to the experimental results. Thus, it can be reliable and proves that the chosen data distribution fits perfectly for both estimations.

\section{Conclusions}

In this study, the fatigue test by the staircase method was performed on crankshaft material made of S34MnV forged steel, and the reliability of the fatigue limit according to the experimental results was predicted. The key findings can be drawn as:

1. The mean fatigue strength and the standard deviation were successfully calculated via the staircase method to be 282 and $10.6 \mathrm{MPa}$, respectively.

2. The staircase method predicted the design fatigue strength stochastically. For example, the design fatigue strength of $95 \%$ survival was estimated to be 264.5 MPa.

3. At the estimated fatigue strength of $260 \mathrm{MPa}$, based on the $97.7 \%$ of survival, all of the specimens were run-out without fracture for up to $1 \mathrm{E} 7$ cycles. It is concluded that the design of fatigue strength can be determined stochastically using the staircase method.

4. All specimens exhibit typical fatigue fractured without being proven to defect material or premature failure on the tested specimens.

The results obtained by authors are reasonable and satisfying. Nevertheless, further analysis is required to perform the conventional fatigue test (S-N curve method) to confirm the validity of the mean fatigue strength of the material employing statistical approach, knowing that the SN master curve for $\mathrm{S} 34 \mathrm{MnV}$ forged steel is not available yet. Afterwards, in-depth analysis of the fractography has to be considered to reveal the post-fracture phenomenon up to micro-level using electron microscope, including the use of fractal theory concept for characterisation. Although from the macro perspective, the defect was unseen, it is recommended to investigate at the microstructure, which might be significantly influential to the scatter result.

Acknowledgement: This research has been carried out from Pukyong National University grant through their facilities, and authors would like to recognise the mutual collaboration between the host organisations.

\section{References}

[1] Fonte M, Infante V, Freitas M, Reis L. Failure mode analysis of two diesel engine crankshafts. Procedia Structural Integrity. 2016;1:313-8.

[2] Fonte M, Duarte P, Anes V, Freitas M, Reis L. On the assessment of fatigue life of marine diesel engine crankshafts. Eng Fail Anal. 2015;56:51-7.

[3] Rodrigues JA, Pandolfelli VC. Insights on the fractal-fracture behaviour relationship. Mater Res. 1998;1(1):47-52.

[4] He JH. A simple approach to one-dimensional convection diffusion equation and its fractional modification for $E$ reaction arising in rotating disk electrodes. J Electroanal Chem (Lausanne). 2019;854:113565.

[5] Kim SJ, Kong YS. Prediction of reliability of fatigue limit of S34MnV steel for marine diesel engine crank throw components. Transaction of Korean Society Mechanical Engineering A. 2016;40(8):751-7. Korean.

[6] Kim SJ, Ahn SH. Estimation of probability distribution of fatigue lives in crank throw forged steel. Journal of the Korean Society for Power System Engineering. 2016;20(3):29-35. Korean.

[7] Korda N, Szörényi B, Li S. Distributed clustering of linear bandits in peer to peer networks, In Proceedings of the 33rd International Conference on International Conference on Machine Learning (ICML'16), New York, NY, USA, 2016, 48. p. 1301-9.

[8] Li S, Karatzoglou A, Gentile C. Collaborative filtering bandits, In Proceedings of the 39th International ACM SIGIR conference on Research and Development in Information Retrieval (SIGIR '16), New York, NY, USA, 2016. p. 539-48.

[9] Kar P, Li S, Narasimhan H, Chawla S, Sebastiani F. Online optimization methods for the quantification problem, In Proceedings of the 22nd ACM SIGKDD International Conference on Knowledge Discovery and Data Mining (KDD '16), New York, NY, USA, 2016. p. 1625-34.

[10] Morrissey R, Nicholas T. Staircase testing of a titanium alloy in the gigacycle regime. Int J Fatigue. 2006;28(11):1577-82.

[11] Wallin KR. Statistical uncertainty in the fatigue threshold staircase test method. Int J Fatigue. 2011;33(3):354-62.

[12] The International Organization for Standardization, ISO 1099: 2017. Metallic materials - Fatigue testing - Axial force-controlled method.

[13] Müller C, Wächter M, Masendorf R, Esderts A. Accuracy of fatigue limits estimated by the staircase method using different evaluation techniques. Int J Fatigue. 2017;100(1):296-307.

[14] Limpert E, Stahel WA, Abbt M. Log-normal distributions across the sciences: keys and clues. Bioscience. 2001;51(5):341-52. 